\title{
Is Coronavirus a new business reality facilitator?
}

\author{
Yulia Vitalievna $\mathrm{Kim}^{1}$ \\ Financial University under the Government of the Russian Federation, Department of English \\ Language and Professional Communication, Moscow, Russia
}

\begin{abstract}
This article considers the spread of the SARS-CoV-2 virus, known as the COVID-19 pandemic, to have far-reaching consequences in terms of employment, production of goods and services worldwide. The article aims to research the dynamics of changes in attitudes towards the disease resulting in reshaping labor market strategies worldwide which include forming stay-at-home economy, digitization of business operations and emerging start-ups to facilitate delivering and consuming goods and services. A few research designs are used in this article with quantitative and case studies being major methods. The main results of this research allow one to associate coronavirus disease with a new business reality facilitator in the global economy rather than a mere risk factor. The topicality and urgency of this article are based on the novelty of the pandemic itself having started less than 2 years ago. This research may be helpful for upcoming fundamental studies in the field of $21^{\text {st }}$-century global emergencies.
\end{abstract}

Keywords: pandemic, coronavirus, digital economy, risk factor, economic development

\section{Introduction}

Ironically, Coronavirus, despite its biological nature, is now considered as a purely external economic risk factor. For the last few decades, the world has faced several virus outbreaks, but none of them ever acquired the global scale and impact that SARS-CoV-2 has. As of June 27, 2021, the cumulative number of infections and death due to COVID-19 worldwide was more than 180 million and 3.9 million respectively [1]. It is obvious that little time has passed since the first wave of contamination occurred in China towards the end of 2019 so that one cannot expect scientists to have much data and insights to fully analyze this issue as a global matter with far-reaching consequences in the following years or even decades.

Nevertheless, much has been said and written regarding the impact of coronavirus on global economies worldwide. The current paper is primarily based on articles in business magazines and scientific journals, rather than on the more fundamental researches that for the most part are still to be published. While examining all the information and speculations concerning this pandemic, one will inevitably notice that it falls into two categories, the

\footnotetext{
${ }^{1}$ Corresponding author: YVKim@fa.ru
} 
first being a descriptive analysis (mainly encountered in scientific journals), whereas the second represents an action research design (business press). For example, E. Smirnov and E. Karelina in their article Assessment of Paradoxes and Risks of the Development of the Global Economy in the Context of the Coronavirus Crisis aim to project how national economies recover from the initial shock caused by the disease outbreak [2]. While we respect the profound work undertaken by these prominent Russian scientists, we cannot ignore the fact that their article, though it provides a deep understanding of the processes that have emerged and the measures that have been taken, treats this pandemic as a mere economic crisis rather than a global shift towards a new economic agenda that is here to stay. In this respect we are more inclined to support the position of another Russian scientist, A, Nikiforova, expressed in her article Labor Market in the Russian Federation in Terms of the Coronavirus Pandemic: The Impact of the Virus on Employment, Production of Goods and Services. While Nikiforova's article restricts the scope of her research to the Russian economy, her findings can be still applicable to understanding global processes as the author links the pandemic with the "beginning of a new, modern society" [3]. The author also states that this disease "will lead to the development of many spheres of public life" [3]. A similar, yet more elaborated, attempt to frame the upcoming economic changes in the realms of the Coronavirus pandemic is shown in A. Tsatsulin's article Digitalization of the Population as a Determinant of the Virtual and Real Labor Market during the Pandemic. The author provides a deep analysis of the current sociopolitical situation in both Russia and the USA to identify digitalization as one of the ways to survive through crisis [4].

This present research aims to fill in the gap in the way Coronavirus is being primarily treated as an emergency which is bound to cease, since the approach of this article is based on the notion that SARS-CoV-2 is a facilitator towards $21^{\text {st }}$-century development of the economic factors paradigm. With that being stated, it is also essential to define the key issues of the research. Can Coronavirus be treated as a development factor? Is Coronavirus an occasional matter or an imminent feature of the economic development of the next decades? These questions are of primary significance for our research. In this article we will (1) provide materials and methods used to gather and analyze data; (2) make an effort to answer the key questions mentioned above; (3) interpret the results obtained in order to situate them within the frame of contemporary researches on the same subject; (4) outline the practical importance of our findings.

\section{Materials and methods}

While our paper is aiming to identify the contribution of the SARS-CoV-2 pandemic towards forming new economic realities, it is necessary to outline the research steps required. First of all, quantitative data is gathered to shape our understanding of how values and output were changed and relocated during the pandemic. For this, we are using secondary data collected by business journalists and economy websites. Since this is descriptive data, gathering observations does not mean any intervention and is unable to determine "cause and effect" relationships. To link the event (pandemic) to its outcome (new economic reality), a "cause and effect" method is applied. We believe that this approach is the most favorable in order to establish the relationship between various processes and provide a projection in the future as it is a standard methodology in our field which does not require justification. Since quantitative method is considered to provide valid generalizable results, it is also important to include/exclude certain criteria to choose 
our variables by using a sampling method which includes both the most affected and improved economic spheres in the last 18 months.

\section{$3 \quad$ Results}

Since our goal is to consider economy formation during the Coronavirus outbreak as a global trend, our study focuses on this process worldwide. Many experts and sources comment on this matter as a significant decrease in economic development. The World Bank, being one of the major international financial institutions, has estimated the proportion of national economies facing recession as the largest in the last 150 years (Fig. 1). According to World Bank data, in 2021 more than $90 \%$ of states are experiencing a downturn and an undoing of the previous years of prosperity and development, with one-third having already been suffering from losses from 2002 to 2018.

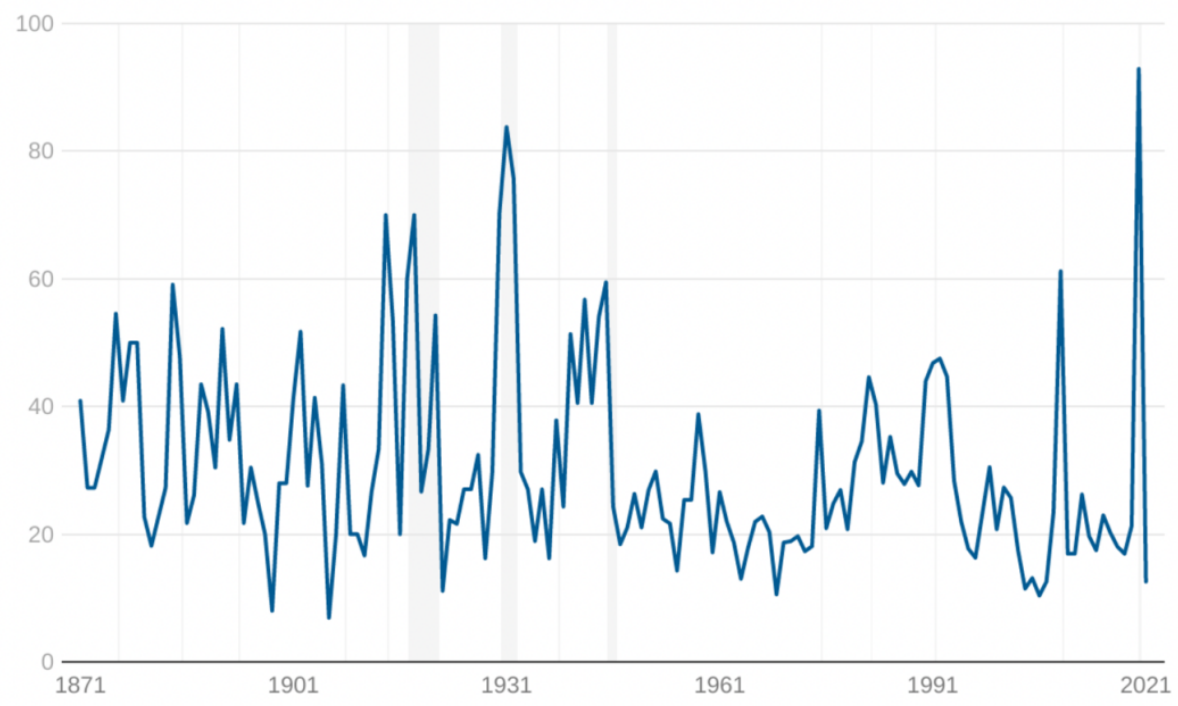

The proportion of economies with an annual contraction in per capita GDP. Shaded areas refer to global recessions. Data for 2020-21 are forecasts.

Source: World Bank

Fig. 1. Share of economies in recession, 1871-2021 [5].

The World Bank also states that the decline in the social economy sphere that was mostly caused by COVID-19 worldwide has "triggered unprecedented collapse in oil demand and a crash in oil prices" [5]. According to Dr. Fatih Birol, Executive Director at IEA (International Energy Agency), "the outbreak of Coronavirus disaster is somewhat distressing the broad range of global energy markets - comprising all types of fossil fuel like renewable, gas and coal, nonetheless its effect on crude oil markets is mainly harsh as it has stopped movement of people and merchandises from moving around, thus causing a severe setback for demand of crude oil" [6]. However, it is also important to note that the economies of developing countries, being mainly dependent on oil prices, have already been viewed as in crisis long before the COVID-19 pandemic outbreak which makes us believe that the notion of Coronavirus being at fault for their declines is not completely justified. In summer 2020, OECD claimed that "prior to the crisis, financing had already fallen short of the spending needs to achieve the SDGs by 2030, and fiscal space was 
limited by rising public debt levels and servicing costs in emerging and developing economies" [7].

While it is essential to note the overall downturn in national economies, there is one process that is observed in all countries throughout the pandemic - start-ups playing a core role in both developed and developing states. It is known that start-ups are considered to be innovative drivers of economic development and able to offer work places that never existed before. "Young firms indeed account for about $20 \%$ of employment but create almost half of new jobs on average across OECD countries, and innovation by young firms significantly contributes to aggregate productivity growth, accounting for half of it in the United States" [8]. Even though the Coronavirus pandemic hindered many innovative firms from continuing to grow, their role in the economic development during the last 18 months has been revolutionary in terms of forging a new business reality.

By 30 March 2020, the early beginning of the pandemic in Europe, it had been estimated that more than 100 start-ups were launched in EU in order to provide social assistance to people left in predicaments [9]. Those include health-tech, mental health and wellbeing, food delivery, fintech, software, transport, remote working, travel, hospitality, events, prop-tech, ed-tech and consumer relations. With this list of different products and services it is clear that customers have gone for online channels since the pandemic started so the businesses have had to respond respectively. According to McKinsey\&Company research [10], the rate at which businesses managed to digitize their services and products exceeds the previous years' speed by almost $30 \%$ worldwide with this acceleration being equal to 7 years development in precrisis circumstances (Fig. 2). Even the Asia-Pacific region, which is mostly developing economies, has increased its digitization by more than $20 \%$ and adopted the proportion of digitized performance that accounts for more than a decade ahead (Fig. 2).

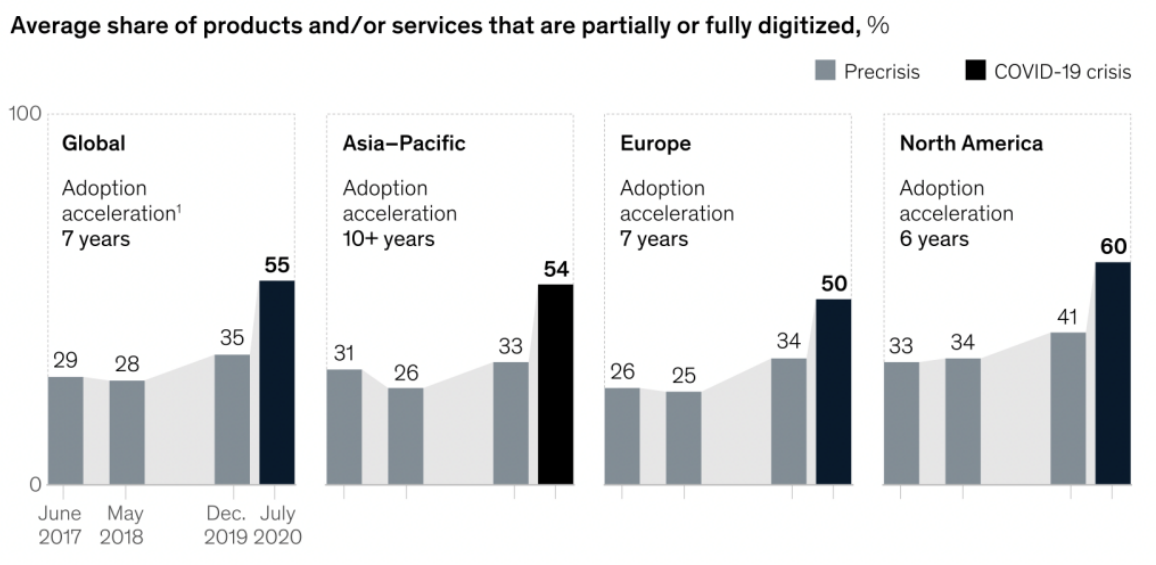

'Years ahead of the average rate of adoption from 2017 to 2019.

Fig 2. Speedup in acquiring digital or digitally enhanced offerings worldwide [10].

\section{Discussion}

While it is obvious that the fastest adoption of digitalized products and services is observed in the businesses which are digital in nature, many companies chose to provide online channels refocusing their performance rather than investing in product development. JPMorgan, AT\&T, Google, Amazon, Nike, Facebook are hustling to virtualize various 
operations with Coronavirus being the catalyst for this business transformation [11]. Amazon alone, since mid-March 2020, has hired 175,000 workers to meet surging demand for online shopping [12]. Nevertheless, a paradigm shift towards digitization and servitization of the economy was already underway prior the pandemic [13]. Yet, many European experts believe that the coronavirus will indeed accelerate the pace of the digital transformation and eventually strengthen digital economy [14]. It is also important to note that those huge leaps that are seen in Fig. 2 were made under huge pressure and may have been facilitated by a decrease in offline portfolios in the meanwhile. Besides, it is also crucial to underline that pre-pandemic rate of very high capacity networks availability in EU did not cover even the half of the households with $44 \%$ in 2019 [15]. However, seeing how traditional offline channels are failing to deliver at a previous rate and scale, new economic realities might need to get used to the Coronavirus threat as a constant factor in the market field which would inevitably transform present economic reality towards larger integration of digital tools.

\section{Conclusion}

The impact of the Coronavirus on the global economy has appeared as a twofold hit. While it is too early to make any predictions regarding the longevity of the state of emergency we still live in, one can be sure that the COVID-19 pandemic is yet to determine the future of business realities. The last 18 months have shown that the disease is not only a risk factor but also a facilitator in forming a new business reality in which digital products and services will be the main drivers of the economy.

\section{References}

1. Coronavirus Resource Center, John Hopkins University (2021). Accessed on: September 25, 2021. [Online]. Available: https://coronavirus.jhu.edu/map.html

2. E.A. Karelina, E.N. Smirnov, Innov Invest, 2, 33-38 (2021)

3. A.A. Nikiforova, Econ Bus, 12-2(70), 181-183 (2020)

4. A.N. Tsatsulin, SPb State Polytech Univ J. Econ, 13(4), 19-35 (2020)

5. The World Bank (2020). Accessed on: September 25, 2021. [Online]. Available: https://www.worldbank.org/en/news/feature/2020/06/08/the-global-economic-outlookduring-the-covid-19-pandemic-a-changed-world

6. IEA (2020). Accessed on: September 25, 2021. [Online]. Available: https://www.iea.org/authors/dr-fatih-birol

7. OECD (2020). Accessed on: September 25, 2021. [Online]. Available: https://www.oecd.org/coronavirus/policy-responses/the-impact-of-the-coronavirus-covi d-19-crisis-on-development-finance-9de00b3b

8. OECD (2020). Accessed on: September 25, 2021. [Online]. Available: https://www.oecd.org/coronavirus/policy-responses/start-ups-in-the-time-of-covid-19-f acing-the-challenges-seizing-the-opportunities-87219267

9. A. Lewin, C. Bilboe, How Startups are supporting Europe's Coronavirus Efforts (2020). Accessed on: September 25, 2021. [Online]. Available: https://sifted.eu/articles/startup-initiatives-coronavirus/ 
10. McKinsey\&Company (2020). Accessed on: September 25, 2021. [Online]. Available: https://www.mckinsey.com/business-functions/strategy-and-corporate-finance/our-insig hts/how-covid-19-has-pushed-companies-over-the-technology-tipping-point-and-transf ormed-business-forever

11. H. McGowan, How the Coronavirus Pandemic Is Accelerating The Future Of Work (2020). Accessed on: September 25, 2021. [Online]. Available:

https://www.forbes.com/sites/heathermcgowan/2020/03/23/the-coronavirus-pandemicaccelerates-the-future-of-work-and-provides-opportunity/?sh=69fa9a $7 \mathrm{~b} 317 \mathrm{f}$

12. Z. Ingilizian, Is Staying In The New Going Out? How The COVID-19 Pandemic Is Fuelling The Stay-At-Home Economy (2020). Accessed on: September 25, 2021. [Online]. Available:

https://www.weforum.org/agenda/2020/05/covid19-coronavirus-digital-economy-cons umption-ecommerce-stay-at-home-online-education-streaming/

13. BDO (2020). Accessed on: September 25, 2021. [Online]. Available: https://www.bdo.com/insights/business-financial-advisory/strategy,-technology-transfo rmation/covid-19-is-accelerating-the-rise-of-the-digital-e

14. DMEXCO (2021). Accessed on: September 25, 2021. [Online]. Available: https://dmexco.com/press/corona-pandemic-will-strengthen-digital-economy/

15. European Commission (2020). Accessed on: September 25, 2021. [Online]. Available: https://ec.europa.eu/commission/presscorner/detail/en/qanda_20_1022 